\title{
Examination of the relationship between health literacy and health perceptions in hemodialysis patients
}

\author{
Mukadder Mollaoğlu ${ }^{1}$, Esra Başer $^{1 *}{ }^{(\mathbb{C}}$, Ferhan Candan $^{2}$
}

\begin{abstract}
Introduction: Patients' high levels of health literacy and positive perception of health are effective in their compliance with the treatment. Objectives: The aim of this study was to examine the relationship between health literacy and the perception of health of hemodialysis patients.

Patients and Methods: In the study, the sampling method was not performed, but it was performed with patients who received hemodialysis treatment and fulfilled the research criteria within the 3-month period. The descriptive study was conducted with a total of 110 patients in two dialysis centers Sivas province of Turkey.

Results: Data were collected using the patient information form, Health Literacy Index (HLI) and perception of health scale (PHS) to determine demographic characteristics. Around $56.4 \%$ of the patients had been receiving hemodialysis treatment for $0-4$ years. The mean score of patients' health literacy was $77.40 \pm 12.94$, and they received the highest score from the appraisal of the subscales. Perception of health mean score was $47.56 \pm 4.10$. When sociodemographic characteristics were examined, health literacy levels were found to be high in males between the ages of 36-45 years, those with a long duration of chronic kidney disease (CKD) and those with higher education level.

Conclusion: According to results patients' health literacy and disease perception were found to be slightly above the middle level. We found a positive relationship between health literacy level and perception of health, and patients' health literacy since the perception of health should be increased in order for the hemodialysis treatment process to be effective.

Keywords: Health literacy, Health perception, Hemodialysis patients

Citation: Mollaoğlu M, Başer E, Candan F. Examination of the relationship between health literacy and health perceptions in hemodialysis patients. J Renal Endocrinol. 2021;7:e11. doi: 10.34172/jre.2021.11.

Copyright $\odot 2021$ The Author(s); Published by Nickan Research Institute. This is an open-access article distributed under the terms of the Creative Commons Attribution License (http://creativecommons.org/licenses/by/4.0), which permits unrestricted use, distribution, and reproduction in any medium, provided the original work is properly cited.
\end{abstract}

\section{Introduction}

Prevalence of chronic kidney disease (CKD) has increased in the world and in our country due to increased prevalence of diabetes, hypertension, obesity and aging $(1,2)$. According to the current classification by The National Kidney Foundation Kidney Disease Outcomes Quality Initiative (NKF-KDOQI), CKD is divided into five stages (3). The 5th phase of CKD is defined as endstage renal failure (ESRD), and at this stage, dialysis, transplantation or only symptom control is required (4). In Turkey, $75.84 \%$ of patients receiving renal replacement therapy also receive hemodialysis treatment (5).

The aim of CKD management is to reduce the progression of ESRD, reduce urinary complications and maintain kidney function (6). Due to the long-term treatment of CKD, the decrease in self-care ability of dialysis patients, loss of competence and the complexity of the life-style change, patients have difficulty in compliance with the process and performing the specified strategies $(7,8)$. The long-term treatment process requires patients' decision making and participation in the process. Patients need to use and access health information in order to be able to effectively make health decisions and implement them. According to the WHO definition "Health literacy is based on general literacy and encompasses people's knowledge, motivation and competences to access, understand, evaluate and apply information on health in order to make judgements and make decisions concerning healthcare, disease prevention and promotion of health to maintain and improve quality of life during their lifetime" (9).

Health literacy is an individual's capacity to obtain, process, and understand basic health information and services required to make appropriate health decisions and act accordingly (10). Nutbeam, who has studies on health literacy, discusses health literacy in three levels 
Implication for health policy/practice/research/ medical education

In a study on hemodialysis patients, we found a positive relationship between health literacy level and perception of health.

as functional/basic, communicative and critical levels. Health literacy enables an effective communication between health service providers and patients receiving health care, allowing both parties to understand each other correctly and fulfill their responsibilities (11). When the literature is examined, it is found that people who high level of health literacy apply to health services in a timely manner, follow the recommendations of health personnel more, improve their health and healthy behavior in a positive way and analyze their health status better (12-15).

When the literature is reviewed, it is seen that the health literacy in patients with CKD is low. In a study conducted in the United States, it was found that $23 \%$ of the patients who received hemodialysis treatment had insufficient health literacy (16). In a study conducted in Turkey, $52.7 \%$ of patients' health literacy levels were found to be problematic or at an insufficient level (17). In a study examining the level of health literacy in elderly individuals with chronic disease, it was found that health literacy was between having little difficulty and having some difficulty according to the mean scores of the scale (18). Inadequate health literacy is associated with poor health outcomes, such as high blood pressure, insufficient dialysis and frequent referral to emergency services in patients with CKD $(19,20)$.

Individual's perceptions, beliefs and attitudes are effective in creating behaviors that affect the health of the individual (21). Perception of health is an indicator of how the individual evaluates his/her health with its biological, psychological and social aspects. The positive perception of the individual's health status enables him/her to control his/her future health status and to develop behaviors that will positively affect his/her health (22). Patient's positive perception of his/her health supports him/her in the treatment of chronic diseases such as CKD where patient's self-management is influential. When there is a situation that threatens the individual's health, the individual responds to it by improving his/her cognitive and emotional perceptions $(23,24)$.

There is a direct relationship between health literacy and the perception of health. In studies conducted, it is seen that scores of health literacy scale decrease as the level of perception of health worsens (18,25-27). Positive health outcomes and health promotion efforts are directly related to health literacy (28).

In the light of the above data, it can be seen that the patient has a one-to-one participation in the course of the long-term treatment of $\mathrm{CKD}$, and that he/she is required to adapt to the lifestyle changes. Health literacy is greatly influential in the compliance of patients with CKD, and its importance in the field of health communication is increasing in terms of improving the health of individuals.

\section{Objectives}

The aim of this study was to determine the levels of health literacy and perception of health of patients with $\mathrm{CKD}$, which is one of the chronic diseases with increasing prevalence and to determine the relationship between health literacy and perception of health in hemodialysis patients, considering that the quality of nursing care to be given for the management of the disease would improve. Our hypothesis is that health literacy and health perception affect each other.

\section{Patients and Methods \\ Study design}

It was a descriptive study in order to examine the relationship between health literacy and the perception of health in hemodialysis patients. The research was carried out at two dialysis centers. In the study, the sampling method was not performed, but it was performed with patients who received hemodialysis treatment and fulfilled the research criteria within the 3-month period. The descriptive study was conducted with a total of 110 patients in two dialysis centers Sivas province of Turkey. One of the center is private and the other was university hospital dialysis center. The study was conducted by one researcher.

The exclusion criteria were as follows; those who had received hemodialysis treatment for less than one year, had difficulty in seeing, hearing and communicating, those under 18 years of age and those who wanted to leave the study were excluded from the study.

\section{Data collection}

Research data were collected through the forms described below.

\section{Patient information form}

It was prepared using the literature. The form consists of 11 questions to determine the sociodemographic characteristics of the patients.

\section{Health literacy index}

The 47-item HLS-EU (Health Literacy Survey In Europe) developed by Sorensen (2013) and the 25-item Health Literacy Index (HLI), which was simplified afterwards by Tochi, Bruzari and Sorenson, were used (9). The validity and reliability study of this scale was conducted by Çimen and Temel, who adapted it to Turkish (17). The scale consists of 25 items and four sub-scales: access to Information contains five items (minimum: 5 points, maximum: 25 points), understanding Information seven items (min: 7 points, max: 35 points), appraisal eight items 
(min: 8 points, max: 40 points) and application five items (min: 5 points, max; 25 points). The minimum score to be received from the scale is 25 and the maximum score is 125. Scale items are answered by participants in the form of Likert as; 5 : I have no difficulty, 4; I have some difficulty, 3; I have little difficulty, 2; I have a lot of difficulties, 1; I am not able to do it/I have no skill/It is impossible Cronbach Alpha coefficient for the internal consistency of the original scale form's subscales ranged from 0.90 to 0.94 (27). In the Turkish version, the Cronbach alpha value was found as 0.92 , while the alpha value of sub-dimensions was 0.62 and 0.79 . Low scores indicate that health literacy is insufficient, while high scores indicate that it is sufficient and very good (18).

Access to information evaluates information about how and where to obtain information about their disease. Understanding information, evaluating and interpreting the data obtained. Appraisal the ability to distinguish the information provided with critical thinking from those that are useful and harmful to it. The application evaluates the ability to make lifestyle changes in line with the information obtained and to apply this information.

\section{Perception of health scale}

It is developed by Diamond et al in 2007 (21). The scales measure previous health, current health, health appearance, resistance/sensitivity to illnesses, health concerns/anxiety, disease tendency, rejection of patient's role and their attitudes towards attending the doctor. It was adapted to Turkish by Kadığlu and Yildız (29). It is a 5-category Likert scale consisting of 15 items. 1st, 5th, 9th, 10th, 11th and 14th items are the expression of positive attitude, while $2^{\text {nd }}, 3^{\text {rd }}, 4^{\text {th }}, 6^{\text {th }}, 7^{\text {th }}, 8^{\text {th }}, 12^{\text {th }}$ and 13 th items are the expression of negative attitude. Positive expressions are scored as "I totally agree $=5$ ", "I agree $=4$ ", "I do not agree=3", "I disagree=2", "I totally disagree=1". Negative attitudes are subject to reverse scoring. Scoring ranges from 15-75. Cronbach's alpha was found as 0.897 according to the sub-scales of the scale. Developed by Diamond et al, this scale was applied to an adult group $(n=322)$, and they found Cronbach's alpha value of subgroups as 0.90 for center of control, 0.91 for self-awareness, 0.91 for certainty and 0.82 for importance of health (21). Kadığlu et al (2012) found that Cronbach's alpha value varied between 0.60 and 0.76 in nursing students (center of control 0,76; Self-Awareness 0,63; Certainty 0,71; Importance of Health 0,60 ) and between 0.53 to 0.73 in students' families (center of control 0.67; self-awareness 0.53 ; certainty 0.73 ; importance of health 0.54 ) in the Turkish version

The patients in the center where the research was conducted were informed about the research. Data collection forms were applied by the investigator for 1520 minutes in the form of a question-answer form after patients, who volunteered to participate in the study, filled out the consent forms.

\section{Ethical issues}

The study was conducted in accordance with the Declaration of Helsinki. Prior to the study, necessary permissions were obtained from the Ethics Committee of Non-Interventional Clinical Investigations Ethics Committee decision date: 26.02.2018 (number\#2018-01/ 22).

\section{Data analysis}

SPSS 22.0 software was used for statistical evaluation of the data. The Kolmogorov-Smirnov test was used for the evaluation of the normality of data, and in the analysis of the descriptive properties of individuals mean \pm standard deviation were used for figures, percentages and continuous variables if the data provide parametric conditions, independent $t$ test was used for two independent groups, and the Kruskal-Wallis test was used for more than two independent groups. The statistical significance level was taken as 0.05 .

\section{Results}

Around $50.9 \%$ of the study sample were female, $54.5 \%$ were between 46-65 years of age, $48.2 \%$ were graduated from primary school. $56.4 \%$ had been receiving hemodialysis treatment for $1-4$ years, $82.7 \%$ had a chronic disease other than $\mathrm{CKD}$, and hypertension ranks first with $60 \%$ among the patients as one of the chronic diseases. The characteristics of participants are presented in Table 1.

When the mean scores of patients' health literacy are examined, the mean score was $77.40 \pm 12.94$ and the appraisal has the highest value, with and the mean score of $26.83 \pm 4.60$ from the scale sub-dimension (Table 2). According to health literacy (item mean score: 3.09 ) scale mean scores of individuals, it is seen that the level of health literacy is between having little difficulty and having some difficulty.

Table 3 shows patients' perception of health levels. Perception of health scale (PHS) mean score was found as 47.56 \pm 4.10 (min: $15.00 \mathrm{max}: 75.00$ ). According to scores, patients' health perceptions were moderate. The scores of the patients from the scale sub-dimensions, respectively center of control $13.96 \pm 2.73$, certainty $11.50 \pm 2.41$, selfawareness $12.00 \pm 1.08$ importance of health $10.61 \pm 1.92$. Health perception scale was obtained from the subdimensions and the highest score was obtained from the self-control sub-dimension.

In Table 4, comparison of the scale scores in terms of the sociodemographic characteristics indicated that the males $(83.57 \pm 10.67)$, those within the age range of 26-35 (106.50 \pm 26.1$)$ and those who work as officer $(95.8 \pm 17.06)$ were found to have significantly higher mean scores of health literacy. Similarly, as education level, duration of hemodialysis treatment and duration of CKD disease increased, health literacy scale score was higher $(P<0.005)$. There was no statistically 
Table 1. Sociodemographic and medical characteristics of patients

\begin{tabular}{|c|c|}
\hline Characteristics & Number () \\
\hline \multicolumn{2}{|l|}{ Age range (y) } \\
\hline $18-25$ & $2(1.8)$ \\
\hline $26-35$ & $2(1.8)$ \\
\hline $36-45$ & $9(8.2)$ \\
\hline $46-65$ & $60(54.5)$ \\
\hline 65 and upper & $37(33.6)$ \\
\hline \multicolumn{2}{|l|}{ Gender } \\
\hline Female & $56(50.9)$ \\
\hline Male & $54(49.1)$ \\
\hline \multicolumn{2}{|l|}{ Marital status } \\
\hline Married & $82(74.5)$ \\
\hline Single & $28(25.4)$ \\
\hline \multicolumn{2}{|l|}{ Occupation } \\
\hline Officer & $5(4.5)$ \\
\hline labourer & $6(5.5)$ \\
\hline Retired & $37(33.6)$ \\
\hline House wife & $53(48.2)$ \\
\hline Self-employment & $8(7.3)$ \\
\hline Student & $1(0.9)$ \\
\hline \multicolumn{2}{|l|}{ Educational degree } \\
\hline Illiterate & $15(13.6)$ \\
\hline Literate (no school) & $23(20.9)$ \\
\hline Primary school & $53(48.2)$ \\
\hline High school & $13(11.8)$ \\
\hline University & $6(5.5)$ \\
\hline \multicolumn{2}{|l|}{ Hemodialysis vintage (y) } \\
\hline $1-4$ & $62(56.4)$ \\
\hline $5-9$ & $29(26.4)$ \\
\hline $10-14$ & $8(7.3)$ \\
\hline$\geq 15$ & $11(10)$ \\
\hline \multicolumn{2}{|l|}{ Comorbidities } \\
\hline Diabetes Mellitus & $56(50.9)$ \\
\hline Hypertension & $66(60)$ \\
\hline Hearth Failure & $31(28.2)$ \\
\hline Coronary artery disease & $3(2.7)$ \\
\hline Other (COPD, gastritis etc. ) & $11(10)$ \\
\hline
\end{tabular}

significant relationship between perception of health and sociodemographic characteristics.

When the relationship between health literacy and health perception was examined, a significant positive correlation was found between two scales (Table 5). As health perception of patients increases, health literacy levels also increase.

\section{Discussion}

Health literacy affects decisions made by people to improve their quality of life, maintain their health and prevent diseases (30). The health literacy is important in chronic cases requiring active participation and compliance of the patient with the treatment process, like hemodialysis treatment (19). When the literature is
Table 2. Hemodialysis patients' HLI and subscales mean scores

\begin{tabular}{lcc}
\hline \multirow{2}{*}{ Subscales } & \multicolumn{2}{c}{ HLI Mean Scores } \\
\cline { 2 - 3 } & Mean \pm SD & Min-Max \\
\hline Access & $14.87 \pm 3.85$ & $5.00-25.00$ \\
Understanding & $18 \pm 5.28$ & $7.00-35.00$ \\
Appraisal & $26.83 \pm 4.60$ & $8.00-40.00$ \\
Application & $17.69 \pm 2.41$ & $5.00-25.00$ \\
Total & $77.40 \pm 12.94$ & $25.00-125.00$ \\
\hline
\end{tabular}

Abbreviation: HLI, Health Literacy Scale; SD, standard deviation.

Table 3. Patients' perception of HLI mean scores

\begin{tabular}{lcc}
\hline \multirow{2}{*}{ Subscales } & \multicolumn{2}{c}{ HLI Mean Scores } \\
\cline { 2 - 3 } & Mean \pm SD & Min-Max \\
\hline Center of control & $13.96 \pm 2.73$ & $5.00-25.00$ \\
Certainty & $11.50 \pm 2.41$ & $4.00-20.00$ \\
Self-awareness & $12.00 \pm 1.08$ & $3.00-15.00$ \\
Importance of health & $10.61 \pm 1.92$ & $3.00-15.00$ \\
Total & $47.56 \pm 4.10$ & $15.00-75.00$ \\
\hline
\end{tabular}

Abbreviation: HLI, Health Literacy Scale; SD, standard deviation.

reviewed, it is observed that the health literacy level of hemodialysis patients is low (31). In our study, according to health literacy (item mean score; 3.09) scale mean scores of individuals, it is seen that the level of health literacy is between having little difficulty and having some difficulty. Patients received the highest score in the appraisal sub-dimension and the lowest score in access to information dimension. When we look at the status of health literacy in the world, in the United States, which is one of the developed countries, $50 \%$ of adults do not have basic health literacy. In a study in which health literacy was assessed in patients with CKD, more than $40 \%$ of the patients had inadequate health-related attitudes (32). In the study with hemodialysis patients, roughly one third $(32.3 \%)$ of participants had inadequate health literacy (33). It can be considered that individuals in the study evaluate the information they have acquired about health, and are competent to determine which medical information is appropriate for them. On the other hand, it is seen that they are lacking in accessing information, obtaining information from the health personnel and using visual literary tools such as the internet and television. This situation can be interpreted to be related to the low education level of the sample group.

Health literacy levels in various chronic diseases were examined. In a study with diabetic patients, health literacy levels were found to be sufficient (34). This result is thought to be related to continuous education of diabetic patients. In a study conducted in Nepal, 51.8\% of hypertension patients and $77.2 \%$ of patients with chronic obstructive pulmonary disease (COPD) were found to have insufficient health literacy (35).

It has been observed that the education of the patients to learn about diseases may prevent the development 
Table 4. Comparison of sociodemographic characteristics and mean scores of the scale

\begin{tabular}{|c|c|c|c|c|}
\hline Features & $\begin{array}{l}\text { HLI } \\
\text { Mean } \pm \text { SD }\end{array}$ & Statistical test & $\begin{array}{l}\text { PHS } \\
\text { Mean } \pm \text { SD }\end{array}$ & Statistical test \\
\hline \multicolumn{5}{|l|}{ Gender } \\
\hline Female & $71.46 \pm 12.20$ & \multirow{2}{*}{$\mathrm{t}:-5.53, P=0.00$} & $47.08 \pm 4.00$ & \multirow[t]{2}{*}{$\mathrm{t}:-1.23, P=0.219$} \\
\hline Male & $83.57 \pm 10.67$ & & $48.05 \pm 4.19$ & \\
\hline \multicolumn{5}{|l|}{ Age (y) } \\
\hline $18-25$ & $72.50 \pm 23.3$ & \multirow{5}{*}{$\mathrm{KW}: 10.25, P=0.036$} & $46.5 \pm 9.19$ & \multirow{5}{*}{$\mathrm{KW}: 6.38, P=0.172$} \\
\hline $26-35$ & $106.50 \pm 26.1$ & & $54.5 \pm 7.77$ & \\
\hline $36-45$ & $81.77 \pm 9.03$ & & $45.33 \pm 3.84$ & \\
\hline $46-65$ & $78.63 \pm 11.9$ & & $48.0 \pm 3.70$ & \\
\hline 65 and upper & $73.05 \pm 12.01$ & & $46.9 \pm 4.05$ & \\
\hline \multicolumn{5}{|l|}{ Occupation } \\
\hline Officer & $95.8 \pm 17.06$ & \multirow{6}{*}{$\mathrm{KW}: 37.56, P=0.00$} & $49.8 \pm 6.01$ & \multirow{6}{*}{$\mathrm{KW}: 2.60, P=0.625$} \\
\hline Laborer & $86.0 \pm 12.85$ & & $46.66 \pm 5.57$ & \\
\hline Retired & $82.9 \pm 11.9$ & & $48.08 \pm 4.35$ & \\
\hline House wife & $70.0 \pm 9.30$ & & $46.88 \pm 3.56$ & \\
\hline Self-employment & $81.5 \pm 5.04$ & & $48.2 \pm 3.7$ & \\
\hline Student & $89.00 \pm 0.00$ & & $53.0 \pm 0.00$ & \\
\hline \multicolumn{5}{|l|}{ Educational degree } \\
\hline Illiterate & $65.87 \pm 10.1$ & \multirow{5}{*}{$\mathrm{KW}: 44.7, P=0.000$} & $46.3 \pm 3.93$ & \multirow{5}{*}{$\mathrm{KW}: 4.44, P=0.349$} \\
\hline Literate (no school) & $69.27 \pm 8.4$ & & $47.5 \pm 3.6$ & \\
\hline Primary school & $79.75 \pm 9.6$ & & $47.8 \pm 3.9$ & \\
\hline High school & $85.76 \pm 12.18$ & & $46.4 \pm 4.6$ & \\
\hline University & $99.16 \pm 13.7$ & & $50.5 \pm 5.61$ & \\
\hline \multicolumn{5}{|c|}{ Hemodialysis vintage (y) } \\
\hline $1-4$ & $74.75 \pm 12.38$ & \multirow{4}{*}{$\mathrm{KW}: 7.48, P=0.058$} & $46.9 \pm 3.9$ & \multirow{4}{*}{$\mathrm{KW}: 2.93, P=0.402$} \\
\hline $5-9$ & $80.34 \pm 14.1$ & & $48.3 \pm 5.05$ & \\
\hline $10-14$ & $79.00 \pm 12.11$ & & $48.6 \pm 2.5$ & \\
\hline$\geq 15$ & $83.45 \pm 10.79$ & & $48.0 \pm 2.7$ & \\
\hline \multicolumn{5}{|l|}{ CKD vintage $(y)$} \\
\hline $1-4$ & $73.48 \pm 12.4$ & \multirow{4}{*}{$\mathrm{KW}: 13.7, P=0.003$} & $46.7 \pm 3.7$ & \multirow{4}{*}{ KW: $6.83, P=0.077$} \\
\hline $5-9$ & $75.36 \pm 11.8$ & & $47.3 \pm 4.4$ & \\
\hline $10-14$ & $84.0 \pm 14.0$ & & $49.6 \pm 4.0$ & \\
\hline$\geq 15$ & $83.0 \pm 10.17$ & & $47.5 \pm 3.9$ & \\
\hline
\end{tabular}

Abbreviations: HLI, Health Literacy Scale; PHS, perception of health scale.

Table 5. Relationship between health literacy and health perception

\begin{tabular}{|c|c|c|c|c|c|c|}
\hline \multirow{2}{*}{ Health Literacy Index } & & \multicolumn{5}{|c|}{ Health Perception Scale } \\
\hline & & Center of Control & Certainty & Self- awareness & Importance of health & Total score of HPS \\
\hline \multirow{2}{*}{ Information access } & $r$ & 0.351 & 0.378 & 0.097 & $-0.164^{*}$ & 0.405 \\
\hline & $P$ & $0.001^{\mathrm{a}}$ & $0.001^{\mathrm{a}}$ & 0.157 & 0.044 & $0.001^{\mathrm{a}}$ \\
\hline \multirow{2}{*}{ Information understand } & $r$ & 0.272 & 0.346 & 0.086 & $-0.170 *$ & 0.328 \\
\hline & $P$ & 0.002 & $0.001^{\mathrm{a}}$ & 0.186 & 0.038 & $0.001^{\mathrm{a}}$ \\
\hline \multirow{2}{*}{ Information appraise } & $r$ & 0.315 & 0.440 & 0.097 & $-0.162 *$ & 0.418 \\
\hline & $P$ & $0.001^{\mathrm{a}}$ & $0.001^{\mathrm{a}}$ & 0.157 & 0.046 & $0.001^{\mathrm{a}}$ \\
\hline \multirow{2}{*}{ Information apply } & $r$ & 0.090 & 0.358 & 0.247 & 0.083 & 0.374 \\
\hline & $P$ & 0.175 & $0.001^{\mathrm{a}}$ & $0.005^{\mathrm{a}}$ & 0.194 & $0.001^{\mathrm{a}}$ \\
\hline \multirow{2}{*}{ Total score of HLI } & $r$ & 0.344 & 0.477 & 0.145 & $-0.160^{*}$ & 0.473 \\
\hline & $P$ & $0.001^{\mathrm{a}}$ & $0.001^{\mathrm{a}}$ & 0.066 & 0.047 & $0.001^{\mathrm{a}}$ \\
\hline
\end{tabular}

Abbreviations: HLI, Health Literacy Scale; PHS, perception of health scale. a $P<0.05$

of symptoms related to disease or dialysis, and that individuals can manage the symptoms more effectively and their adaptation to the disease can be better achieved, thereby improving the quality of life $(36,37)$. Education of the patient receiving dialysis in Turkey are provided by the medical staff. In every dialysis session, the necessary information is given by the visit and controller and other healthcare professionals, especially nurses.

Chronic diseases adversely affect individuals' perception of health. CKD is a chronic condition and necessitates 
the individual to re-define the definition of health and to ensure the intrinsic motivation in adapting to the disease (38). As a result of the study, the overall total score of PHS was found as $47.56 \pm 4.10$. It can be said that patients' health perceptions are moderate. In the study performed by Yanmıs and Ergüney with hemodialysis patients, the patients' perceptions of health levels were similar to that of our study (39). The patients received the highest score from the subscales of health perception in the dimension of self-awareness. It can be interpreted as that people are aware that protecting their health is in their own hands. In a study conducted by Jansen et al, positive perception of disease and treatment was found to be related to the higher sense of self-determination and autonomy (40). Again, in another study conducted by Jansen, it was concluded that hemodialysis treatment significantly affected their daily lives and that their personal controls were at a low level (41). And another study with diabetic patients found that significant direct pathways were determined from empowerment perceptions to health literacy from selfefficacy to self-care behaviors (10).

In our study, health literacy scale scores of male patients, young people, officers and those with high education levels were found to be higher when health literacy and sociodemographic characteristics were compared. Similarly to our study, in the study conducted by Çimen and Temel, health literacy scores increased as age decreased and education level increased (18). In the study conducted by Toci et al with elderly individuals, it was found that health literacy scores decreased with increasing age (27). This result can be explained by the low level of education of elderly individuals in our country. Because, according to 2015 data the proportion of illiterate individuals is 7.9 in Turkey (42). Health literacy rates of patients increase with the increase of education level. As a result, patients' awareness against diseases is increasing.

Similarly to our study, Özdemir et al reported that women had lower health literacy in their study with 456 people using preventive health services (43). It can be interpreted that the result we obtained could be related to the low education level of women in our sample. On the other hand, in some studies, women's health literacy levels were found to be higher $(9,18)$.

In the studies, it was found that the level of knowledge increased as the patients' kidney disease progressed and the interviews with health professionals increased (44). In the present study, health literacy scale scores increased as the duration of CKD and hemodialysis treatment increased. Increasing knowledge about CKD in relation to health literacy can increase the self-care capacities of patients, ensure the effective use of the health system and improve the quality of health personnel-patient relations (16). As the duration of diagnosis increases, patients need to solve their own health problems with experience. For this reason, patients' health perceptions and information increase in order to improve their health.
Health literacy is associated with perceived health status. Because people with the adequate health literacy are more likely to take action to solve their health problems if they actively learn about their health and feel that their health is deteriorating (45). In our study, a positive correlation was found between the health literacy and the perception of health. Health literacy scale scores of those with the high perception of health were also high. When the literature is examined, it has been shown that there is a relationship between the health literacy and the perception of health (46-48).

\section{Conclusion}

In our study, examining the findings, it was concluded that there is a relationship between the health literacy and the perception of health. Additionally, the levels of health literacy and health perception of hemodialysis patients in the study were found to be moderate level. When the data were evaluated, it was concluded that the patients had difficulty in accessing the information but had no difficulty in applying the information about their health. Studies have shown that there is a relationship between compliance with dialysis treatment and health literacy and perception of health. The health literacy and health perceptions of the patients should be increased in order for the hemodialysis treatment process to be effective. At this stage, it is seen that nurses and health personnel interacting with the patient have an important role in evaluating the patients and providing education and information when necessary. Moreover, the development of health literacy can be achieved through the joint efforts of different parties such as education sector, non-governmental organizations, academic environment, media and communication sector, as well as the health sector.

Within the limits of this study was to be performed in only one dialysis unit. The number of patients in the sample is small. However, very few studies have been conducted in our country. Therefore, this study is one of the pioneering studies. In the larger population it will be a guide for further studies.

\section{Limitations of the study}

Within the limits of this study was to be performed in only one dialysis unit. The number of patients in the sample is small. However, very few studies have been conducted in our country. Therefore, this study is one of the pioneering studies. In the larger population it will be a guide for further studies.

\section{Acknowledgements}

We would like to extend our sincere thanks to all the hemodialysis patients for their invaluable contributions to the study.

Authors' contribution

$M M, E B$ and FC were the principal investigators of the study. MM and $\mathrm{EB}$ were included in preparing the concept and design. MM and FC revisited the manuscript and critically evaluated the intellectual 
contents. All authors participated in preparing the final draft of the manuscript, revised the manuscript and critically evaluated the intellectual contents. All authors have read and approved the content of the manuscript and confirmed the accuracy or integrity of any part of the work.

Conflicts of interest

The authors declare that they have no competing interests.

Ethical considerations

Ethical issues (including plagiarism, data fabrication, double publication) have been completely observed by the authors.

\section{Funding/Support}

The author(s) received no financial support for the research, authorship, and/or publication of this article.

\section{References}

1. Avodele OE \& Alebiosu CO. Burden of chronic kidney disease: An international perspective. Advances in Chronic Kidney Disease. 2010;17:215-24. doi: 10.1053/j.ackd.2010.02.001

2. Dhaidan FA. Prevalence of end stage renal disease and associated conditions in hemodialysis Iraqi patients. Int J Res Med Sci. 2018;6:1515-8. doi: 10.18203/2320-601

3. Vera GTO. Chronic Renal Failure and the Uremic Syndrome. In: Lerma E, Berns JS \& Nissenson A, eds. Current Diagnosis and Treatment: Nephrology And Hypertension. McGraw-Hill Education/Medical; 2009.

4. Anderson S, Halter JB, Hazzard WR, Himmelfarb J, Horne FM, Kaysen GA, et al. Prediction, progression and outcomes of chronic kidney disease in older adults. J Am Soc Nephrol. 2009;20:1199-209. doi: 10.1681/ASN.2008080860

5. Süleymanlar G, Ateş K, Seyahi N (Ed.) Nephrology, Dialysis and Transplantation 2017-Report in Turkey. Ankara: Turkish Society of Nephrology Publications; 2018;1-6.

6. James MT, Hemmelgarn BR, Tonelli M. Early recognition and prevention of chronic kidney disease.[Erratum appears in Lancet.17;376(9736):162]. Lancet 2010;375:1296-309. doi: 10.1016/S0140-6736(09)62004-3.

7. Mollaoğlu M. Diyaliz Hastalarında Yeti Yitimi, Günlük Yaşam Aktiviteleri ve Öz Yeterlilik Durumu. [Disability, Activities of Daily Living and Self-Efficacy in Dialysis Patients]. TAF Preventive Medicine Bulletin. 2011;10:181-186.

8. Jain N, Reilly RF. Effects of dietary interventions on incidence and progression of CKD. Nat Rev Nephrol. 2014;10(12):71224. doi: 10.1038/nrneph.2014.192.

9. Sørensen K, Van den Broucke S, Pelikan JM, Fullam J, Doyle $\mathrm{G}$, Slonska Z, et al. Measuring health literacy in populations: illuminating the design and development process of the European Health Literacy Survey Questionnaire (HLS-EU-Q). BMC Public Health. 2013;13(1):948. doi: 10.1186/14712458-13-948.

10. Lee EH, Lee YW, Moon SH. A structural equation model linking health literacy to self-efficacy, self-care activities, and health-related quality of life in patients with type 2 diabetes. Asian Nurs Res. 2016;10:82-87.

11. Nutbeam D. Health literacy as public health goal: a challenge for contemporary health education and communication strategies into the 21st century. Health Promot Int. 2000; 15:259-67. doi: 10.1093/heapro/15.3.259

12. Osborne H. Health Literacy. From A to Z. 2nd ed. Jones \& Bartlett. 2013.

13. Safeer Richard S, Jann K. Health literacy: the gap between physicians and patients. Am Fam Physician. 2005;72:463-468.

14. Sudore RL, Yaffe K, Satterfield S, Harris TB, Mehta KM, Simonsick EM, et al. Limited literacy and mortality in the elderly: the health, aging, and body composition study. J Gen Intern Med. 2006;21:806-12.

15. Campbell ZC, Stevenson JK, McCaffery KJ, Jansen J, Campbell $\mathrm{KL}$, Lee VWS, et al. Interventions for improving health literacy in people with chronic kidney disease. Cochrane Database Syst Rev. 2016;(2):CD012026. doi: 10.1002/14651858. CD012026

16. Frasen SDS, Roderick PJ, Casey M, Taal MW, Yuen HM, Nuthbeam D. Prevalence and associations of limited health literacy in chronic kidney disease: a systematic review. Nephrol Dial Transplant. 2013;28:129-37. doi: 10.1093/ndt/ gfs 371

17. Çimen Aras Z, Bayık Temel A. Sağlık Okuryazarlığı Ölçeğinin Türkçe Formunun Geçerlilik ve Güvenirliğinin Değerlendirilmesi. [Evaluation of Validity and Reliability of the Turkish Version of Health Literacy Scale]. FNJN. 2017;25(2):85-94.

18. Çimen Z, Temel AB. Kronik hastalığı olan yaşıı bireylerde sağlık okuryazarlığı, sağlık algısı ve ilişkili faktörler. [Investigation of health literacy, perception of health and related factors in elderly patients with chronic illnessjournal of Ege University Nursing Faculty. 2017;33:105-125.

19. Devraj R, Gordon EJ. Health literacy and kidney disease: Toward a new line of research. Am J Kidney Dis. 2009;53:8849. doi: 10.1053/j.ajkd.2008.12.028

20. Green JA, Mor MK, Shields AM, Sevick MA, Arnold RM, Palevsky PM, et al. Associations of health literacy with dialysis adherence and health resource utilization in patients receiving maintenance hemodialysis. Am J Kidney Dis. 2013;62:73-80. doi: 10.1053/j.ajkd.2012.12.014.

21. Diamond JJ, Becker JA, Arenson CA, Chambers CV, Rosenthal MP. Development of a scale to measure adults' perceptions of health: priliminary findings. J Community Psychol. 2007;35:557-61. doi: 10.1002/jcop.20164.

22. Bezner JR. Promoting health and wellness: implications for physical therapist practice. Phys Ther. 2015;95:1433-44. doi: 10.2522/ptj.20140271

23. White K, Issac MS, Kamoun C, Leygues J, Cohn S. The THRIVE model: A framework and review of internal and external predictors of coping with chronic illness. Health Psychol Open. 2018;5(2):1-14.

24. Fernandez DM, Larson JL, Zikmund-Fisher BJ. Associations between health literacy and preventive health behaviors among older adults: findings from the health and retirement study. BMC Public Health. 2016;16:596.

25. Tokuda Y, Doba N, Butler JP, Paasche-Orlow MK. Health Literacy and Physical and Psychological Wellbeing in Japanese Adults. Patient Education and Counseling. 2009;75:411-7. doi: 10.1016/j.pec.2009.03.031.

26. Mancusa MJ. Health Literacy: A Concept/Dimensional Analysis. Nurs Health Sci. 2008;10:248-255. doi: 10.1111/j.1442-2018.2008.00394.x.

27. Toci E, Burazeri G, Sorenson K, Brand H. Health literacy and socioeconomic characteristics among older people in transitional Kosovo. Br J Med Med Res. 2013;3(4):1646-58.

28. Sykes S, Wills J, Rowlands G, Popple K. Understanding critical health literacy: a concept analysis. BMC Public Health. 2013;13:150. doi: 10.1186/1471-2458-13-150

29. Kadıoğlu H, YıldızA. SağlıkAlgısı Ölçeği'nin Türkçe Çevriminin Geçerlilik ve Güvenilirliği. [Validity and Reliability of Turkish Version of Perception of Health Scale]. Turkiye Klinikleri J Med Sci. 2012;32:47-53.

30. Kickbusch I, Pelikan JM, Apfel F, Tsouros AD. Health Literacy. Denmark: WHO Regional Office for Europe' 2013.

31. Cavanaugh KL, Wingard RL, Hakim RM, Eden S, Shintani A, Wallston KA, et al. Low health literacy associates with increased 
mortality in ESRD. J Am Soc Nephrol. 2010;21:1979 -85.

32. Lambert K, Mullan J, Mansfield K, Lonergan M. A crosssectional comparison of health literacy deficits among patients with chronic kidney disease. J Health Commun. 2015;20:1623. doi: 10.1080/10810730.2015.1080329.

33. Grubbs V, Gregorich SE, Perez-Stable, EJ, Hsu CY. Health literacy and access to kidney transplantation. Clin J Am Soc Nephrol. 2009;4:195-200.

34. Ishikawa H, Takeuchi T, Yano E. Measuring functional, communicative, and critical health literacy among diabetic patients. Diabetes Care. 2008;31:874-879.

35. Shrestha A, Singh SB, Khanal VK, Bhattarai S, Maskey R, Pokharel PK. Health literacy and knowledge of chronic diseases in Nepal. Health Lit Res Pract. 2018;2:e221.

36. Ebrahimi H, Sadeghi M, Amanpour F, Dadgari A. Influence of nutritional education on hemodialysis patients' knowledge and quality of life. Saudi J Kidney Dis Transpl. 2016;27:250.

37. Narva AS, Norton JM, Boulware LE. Educating patients about CKD: the path to self-management and patient-centered care. Clin J Am Soc Nephrol. 2016;11:694-703.

38. Akyol AD. Hemodiyaliz Hastalarında Yaşam Kalitesini Etkileyen Faktörlerin İncelenmesi. [Investigation of Factors Affecting the Quality of Life in Hemodialysis Patients]. Journal of Nephrology Nursing. 2016;11:7-33.

39. Yanmış S, Ergüney H. Sağlık algısının hemodiyalize bağımlı olan bireylerde diyet ve sıvı kısıtlamasına uyumsuzluğuna etkisi [ The effect of health perception on nonadherence to diet and fluid restriction in hemodialysis dependent individuals] [thesis]. Atatürk University, Health Science Instution; 2015.

40. Jansen DL, Heijmans MJ, Rijken M, Spreeuwenberg P, Grootendorst DC, Dekker FW, et al. Illness perceptions and treatment perceptions of patients with chronic kidney disease: different phases, different perceptions?. Br J Health Psychol. 2013;18:244-262.doi: 10.1111/bjhp.12002.

41. Jansen DL, Grootendorst DC, Rijken M, Heijmans $M$, Kaptein AA, Boeschoten EW, Dekker FW. Pre-dialysis patients' perceived autonomy, self-esteem and labor participation: associations with illness perceptions and treatment perceptions. A cross-sectional study. BMC Nephrol. 2010;11:35. doi: 10.1186/1471-2369-11-35.

42. Turkish Statistical Institute (TSI). Turkey in Statistics. 2015. https://ec.europa.eu/eurostat/documents/7330775/7339623/ Turkey+_in_statistics_2015.pdf/317c6386-e51c-45de-85b0ff671e3760f8. Accessed February 4, 2020.

43. Özdemir H, Alper Z, Uncu Y, Bilgel N. Health literacy among adults: a study from Turkey. Health Educ Re. 2010;25:464477. doi: 10.1093/her/cyp068

44. Finkelstein FO, Story K, Firanek C, Barre P, Takano T, Soroka $\mathrm{S}$, et al. Perceived knowledge among patients cared for by nephrologists about chronic kidney disease and end-stage renal disease therapies. Kidney Int. 2008;74:1178-84. doi: 10.1038/ki.2008.376.

45. Deniz SŞ, Özer Ö, Sonğur C. Effect of health literacy on health perception: An application in individuals at age 65 and older. Social work in public health. 2018;33:85-95.

46. Chang LC. Health literacy, self-reported status and health promoting behaviours for adolescents in Taiwan. J Clin Nurs. 2010;20:190-6. doi: 10.1111/j.1365-2702.2009.03181.

47. Jovic-Veanes A, Bejgovic-Mikanovic V, Marinkovic J. Functional health literacy among primary health-care patients: data from the Belgrade pilot study. J Public Health. 2009;31:490-95. doi: 10.1093/pubmed/fdp049.

48. Sentell T, Zhang W, Davis J, Baker KK, Braun KL. The influence of community and individual health literacy on self-reported health status. J Gen Intern Med. 2013;29:298-304. doi: 10.1007/s11606-013-2638-3 